\title{
Mechanism of protection of adenosine from sulphate radical anion and repair of adenosine radicals by caffeic acid in aqueous solution
}

\author{
M SUDHA SWARAGA, L CHARITHA and M ADINARAYANA* \\ Department of Chemistry, Osmania University, Hyderabad 500 007, India \\ e-mail: mundra_adinarayana@hotmail.com
}

MS received 4 February 2005

\begin{abstract}
The photooxidation of adenosine in presence of peroxydisulphate (PDS) has been studied by spectrophotometrically measuring the absorbance of adenosine at $260 \mathrm{~nm}$. The rates of oxidation of adenosine by sulphate radical anion have been determined in the presence of different concentrations of caffeic acid. Increase in [caffeic acid] is found to decrease the rate of oxidation of adenosine suggesting that caffeic acid acts as an efficient scavenger of $\mathrm{SO}_{4}^{--}$and protects adenosine from it. Sulphate radical anion competes for adenosine as well as for caffeic acid. The quantum yields of photooxidation of adenosine have been calculated from the rates of oxidation of adenosine and the light intensity absorbed by PDS at $254 \mathrm{~nm}$, the wavelength at which PDS is activated to sulphate radical anion. From the results of experimentally determined quantum yields $\left(\phi_{\text {exptt }}\right)$ and the quantum yields calculated $\left(\phi_{\text {cal }}\right)$ assuming caffeic acid acting only as a scavenger of $\mathrm{SO}_{4}^{--}$show that $\phi_{\text {exptl }}$ values are lower than $\phi_{\text {cal }}$ values. The $\phi^{\prime}$ values, which are experimentally found quantum yield values at each caffeic acid concentration and corrected for $\mathrm{SO}_{4}^{--}$scavenging by caffeic acid, are also found to be greater than $\phi_{\text {exptl }}$ values. These observations suggest that the transient adenosine radicals are repaired by caffeic acid in addition to scavenging of sulphate radical anions.
\end{abstract}

Keywords. Repair by caffeic acid; repair of adenosine radicals; oxidation by sulphate radical anions.

\section{Introduction}

It is generally accepted that the lethal effects of ionizing radiation on cellular systems involve radical induced chemical changes in essential biomolecules, particularly deoxyribonucleic acid (DNA). ${ }^{1}$ It is known that hydroxycinnamic acids are natural antioxidants and their antioxidant and antifungal activity is mainly due to their ability to scavenge several oxidizing free radicals. In recent times focus is on the protective action of naturally occurring antioxidants and in this connection studies involving caffeic acid assume importance due to the wide spread occurrence of this antioxidant in nature. When DNA is subjected to ionizing radiation many different changes can occur in $\mathrm{DNA}^{2}$, ranging from various kinds of base modifications to single and double strand breaks. Even though sugar radicals are actually responsible for strand break formation in DNA, experimental results clearly indicate that base radicals can contribute significantly via transfer of radical sites

*For correspondence from base moiety to sugar moiety. Strand breaks are considered to be a very serious kind of damage to DNA. ${ }^{3,4}$

Ionizing radiation causes damage to DNA by direct effect and indirect effect. The former is caused by the absorption of the ionizing radiation by the DNA molecule itself, the later by water radicals generated upon absorption of the ionizing radiation by water. It is very difficult to distinguish experimentally between these two modes of damage formation in DNA. On the absorption of ionizing radiation, DNA molecule undergoes a chemical change giving radical cation which on spontaneous deprotonation gives DNA radical, the chemistry of which is similar to DNA radicals produced by $\mathrm{OH}$ radicals. In order to mimic and understand the mechanism of direct effect of ionizing radiation on DNA model compounds, oxidation of a series of purine bases by $\mathrm{SO}_{4}^{--}$have been studied and a probable mechanism is suggested. ${ }^{5}$

In order to understand the mechanism of protection from sulphate radical anion and to characterize the transient radicals of the substrate a systematic kinetic study of oxidation of adenosine in presence and 
absence of caffeic acid has been carried out. In this paper we report the results on the protection of adenosine from sulphate radical anion by caffeic acid. Further an attempt has also been made to evaluate the extent of repair of adenosine radicals by caffeic acid.

\section{Experimental}

Adenosine and peroxydisulphate (PDS) were purchased from E.Merck, while caffeic acid was from Sigma. All solutions were prepared using double distilled water. Stock solutions of adenosine and caffeic acid were always freshly prepared and were deaerated by bubbling nitrogen. The solution of potassium salt of peroxydisulphate was prepared using double distilled water and standardised using cerimetry using ferroin indicator. Peroxydisulphate solution was added to a measured excess of ferrous ammonium sulphate, and back titrated with a standard ceric ammonium sulphate solution as reported by Kapoor et $a l^{6}$. At room temperature this reaction is rapid enough for analytical purposes and equivalency of ferrous ion to peroxydisulphate is 2 to 1 . Required amounts of caffeic acid were then injected as aqueous solution into the mixture of adenosine and PDS solutions present in a specially designed 1$\mathrm{cm}$ path length quartz cuvette which is suitable for both irradiations in the quantum yield reactor as well as for absorbance measurements. The absorbance measurements were made at $260 \mathrm{~nm}$, which is the $\lambda_{\max }$ of adenosine on a HITACHI UV-visible spectrophotometer (model 3410). Irradiations were performed at room temperature $\left(25^{\circ} \mathrm{C}\right)$ with highpressure mercury lamp using Quantum yield reactor model QYR-20. The irradiations were interrupted at definite intervals of time and the absorbance was noted from which the rate of reaction and the quantum yields of oxidation are calculated. The light intensity at $254 \mathrm{~nm}$ was measured by peroxydisulphate chemical actinometry. ${ }^{7}$ The light intensity absorbed by PDS was calculated using the following equation:

$$
I_{\mathrm{PDS}}=\frac{\varepsilon_{\mathrm{PDS}}[\mathrm{PDS}]}{\varepsilon_{\mathrm{PDS}}[\mathrm{PDS}]+\varepsilon_{\text {adenosine }}[\text { adenosine }]} \times I_{t},
$$

$I_{\mathrm{PDS}}=$ the intensity of light absorbed by peroxydisulphate in a reaction mixture, $I_{t}=$ total intensity of light measured from peroxydisulphate actinometry, $\varepsilon_{\mathrm{PDS}}=$ the molar absorption coefficient of peroxydisulphate at $254 \mathrm{~nm}\left(24 \cdot 1 \mathrm{dm}^{3} \mathrm{~mol}^{-1} \mathrm{~cm}^{-1}\right), \varepsilon_{\text {adenosine }}=$ the molar absorption coefficient of adenosine at $254 \mathrm{~nm}\left(14200 \mathrm{dm}^{3} \mathrm{~mol}^{-1} \mathrm{~cm}^{-1}\right)$.

\section{Results and discussion}

$\mathrm{N}_{2}$-saturated aqueous solutions of the reaction mixture containing adenosine $\left(0.5 \times 10^{-4} \mathrm{~mol} \mathrm{dm}^{-3}\right)$, PDS $\left(4.0 \times 10^{-4} \mathrm{~mol} \mathrm{dm}^{-3}\right)$ and caffeic acid were irradiated and the absorbance at $260 \mathrm{~nm}\left(\lambda_{\max }\right.$ of adenosine) with time were noted (table 1 , figure 1$)$. The

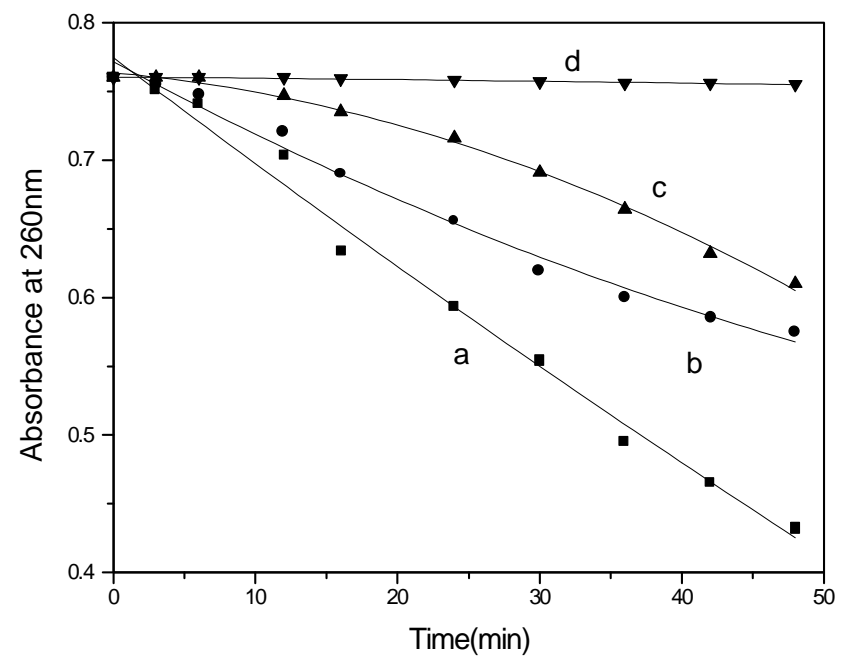

Figure 1. Effect of caffeic acid on the photooxidation of adenosine by PDS [adenosine] $=5.00 \times 10^{-5} \mathrm{~mol} \mathrm{dm}^{-3}$, $[\mathrm{PDS}]=4.00 \times 10^{-4} \mathrm{~mol} \mathrm{dm}{ }^{-3}$, [caffeic acid] $=$ (a) $0 \cdot 0$, (b) $5.00 \times 10^{-6} \mathrm{~mol} \mathrm{dm}^{-3}$, (c) $1.00 \times 10^{-5} \mathrm{~mol} \mathrm{dm}^{-3}$, (d) $5.00 \times$ $10^{-5} \mathrm{~mol} \mathrm{dm}^{-3}$. Light intensity $=1.01 \times 10^{15}$ quanta s ${ }^{-1}$.

Table 1. Photooxidation of adenosine in presence of peroxydisulphate at various [caffeic acid] in aqueous anoxic solutions.

[adenosine $]=5.00 \times 10^{-5} \mathrm{~mol} \mathrm{dm}^{-3}, \quad[\mathrm{PDS}]=4.00 \times 10^{-4}$ mol dm${ }^{-3}$, temp $=298 \mathrm{~K}$, light intensity $=1.01 \times 10^{15}$ quanta $\mathrm{s}^{-1}$ at $254 \mathrm{~nm}$

\begin{tabular}{lcccc}
\hline & \multicolumn{4}{c}{$\begin{array}{c}\text { Absorbance at } 260 \mathrm{~nm} \text { in presence } \\
\text { of varying [caffeic acid] }(\mu \mathrm{M})\end{array}$} \\
\cline { 2 - 5 } $\begin{array}{l}\text { Irradiation } \\
\text { time }(\mathrm{min})\end{array}$ & 0.00 & 5.00 & 10.00 & $50 \cdot 00$ \\
\hline 0 & 0.760 & 0.760 & 0.760 & 0.760 \\
3 & 0.752 & 0.755 & 0.760 & 0.760 \\
6 & 0.741 & 0.747 & 0.760 & 0.760 \\
12 & 0.703 & 0.721 & 0.747 & 0.760 \\
18 & 0.634 & 0.690 & 0.735 & 0.759 \\
24 & 0.594 & 0.656 & 0.716 & 0.758 \\
30 & 0.554 & 0.620 & 0.691 & 0.757 \\
36 & 0.495 & 0.600 & 0.664 & 0.756 \\
42 & 0.465 & 0.585 & 0.632 & 0.756 \\
48 & 0.432 & 0.575 & 0.610 & 0.755 \\
\hline
\end{tabular}


Table 2. Effect of [caffeic acid] on the quantum yields of photooxidation of adenosine in presence of peroxydisulphate (PDS) under anoxic conditions.

$[\mathrm{PDS}]=4.00 \times 10^{-4} \mathrm{~mol} \mathrm{dm}{ }^{-3}$, [adenosine $]=5.00 \times 10^{-5} \mathrm{~mol} \mathrm{dm}^{-3}$, light intensity $=1.01 \times 10^{15}$ quanta s$^{-1}$ at $254 \mathrm{~nm}, \mathrm{pH} \sim 7 \cdot 5$, temp $=298 \mathrm{~K}$

\begin{tabular}{|c|c|c|c|c|c|c|c|}
\hline $\begin{array}{l}10^{5} \times[\text { caffeic acid }] \\
\left(\mathrm{mol} \mathrm{dm}^{-3}\right)\end{array}$ & $\begin{array}{c}10^{9} \times \text { rate } \\
\left(\mathrm{mol} \mathrm{dm}^{-3} \mathrm{~s}^{-1}\right)\end{array}$ & $\phi_{\text {exptl }}$ & $P$ & $\phi_{\text {cal }}$ & $\phi^{\prime}$ & $\%$ Scavenging & \% Repair \\
\hline $0 \cdot 000$ & $7 \cdot 57$ & $0 \cdot 454$ & $1 \cdot 00$ & $0 \cdot 454$ & $0 \cdot 454$ & $0 \cdot 00$ & $0 \cdot 00$ \\
\hline $0 \cdot 500$ & $4 \cdot 25$ & $0 \cdot 255$ & $0 \cdot 685$ & $0 \cdot 310$ & $0 \cdot 372$ & $31 \cdot 5$ & $18 \cdot 0$ \\
\hline $1 \cdot 00$ & $2 \cdot 01$ & $0 \cdot 123$ & $0 \cdot 530$ & $0 \cdot 240$ & $0 \cdot 232$ & $47 \cdot 0$ & $48 \cdot 9$ \\
\hline $5 \cdot 00$ & $0 \cdot 120$ & $0 \cdot 007$ & $0 \cdot 170$ & $0 \cdot 077$ & $0 \cdot 043$ & $83 \cdot 0$ & $91 \cdot 0$ \\
\hline
\end{tabular}

absorbances of adenosine in the reaction mixture at different intervals of irradiation time have been obtained by subtracting the contribution of absorbance of caffeic acid by carrying out a parallel experiment with caffeic acid alone at the same time intervals of time measured under similar experimental conditions of the oxidation of adenosine by $\mathrm{SO}_{4}^{--}$in presence of caffeic acid. From these the rates of oxidation of adenosine were calculated from the plots of absorbance versus time using a microcal origin computer program on personal computer (table 2, figure 1). The initial rates of oxidation of adenosine by sulphate radical anion have been found to decrease with increase in [caffeic acid] (table 2, figure 1). The quantum yields of oxidation of adenosine were calculated from the rates of oxidation of adenosine by sulphate radical anion and the light intensity absorbed by PDS at $254 \mathrm{~nm}$, the wavelength at which PDS is activated to sulphate radical anions. The quantum yields of oxidation of adenosine $\left(\phi_{\text {expt1 }}\right)$ at different [caffeic acid] are presented in table 2. The $\phi_{\text {exptl }}$ values were found to decrease with increasing concentration of caffeic acid.

Caffeic acid did not undergo any chemical change on shining the light in the absence of peroxydisulphate (PDS). It has very high molar absorption coefficient $\left(7500 \mathrm{dm}^{3} \mathrm{~mol}^{-1} \mathrm{~cm}^{-1}\right)$ at $254 \mathrm{~nm}$ wavelength at which peroxydisulphate is activated to give $\mathrm{SO}_{4}^{--}$ radicals. Due to this more light is being absorbed by caffeic acid and the concentration of $\mathrm{SO}_{4}^{--}$radicals produced from activation of PDS should decrease with increase in concentration of caffeic acid. However, during the photo oxidation of caffeic acid alone in presence of peroxydisulphate we have reported ${ }^{8}$ that the initial rates of oxidation of caffeic acid are found to increase with increase in concentration of caffeic acid. These results could be explained by assuming that the caffeic acid is excited by the absorption of light at $254 \mathrm{~nm}$ by acting as an inner filter, which subsequently transfers energy to peroxydisul- phate to give $\mathrm{SO}_{4}^{--}$radicals by acting as a sensitizer. Thus the efficiency of production of $\mathrm{SO}_{4}^{--}$radicals increases, which increases the rate of oxidation of caffeic acid.

Therefore, in the present work we propose that caffeic acid as well as adenosine act as sensitizers and transfer energy to peroxydisulphate to create $\mathrm{SO}_{4}^{--}$radicals. In the system there is competition between adenosine and caffeic acid for $\mathrm{SO}_{4}^{--}$, the relative amounts of $\mathrm{SO}_{4}^{--}$reacting with adenosine decreases with increasing [caffeic acid]. The rate constant of the reaction of the sulphate radical anion with adenosine has been reported ${ }^{9}$ to be $2.7 \times$ $10^{9} \mathrm{dm}^{3} \mathrm{~mol}^{-1} \mathrm{~s}^{-1}$. The rate constant for the reaction of sulphate radical anion with caffeic acid has been calculated by the adenosine competition method, which is very similar to the one chosen by Akhalaq et $a l^{10}$ to determine the rate constant for the reaction of $\mathrm{OH}$ radicals with polyhydric alcohols in competition with KSCN. In the photolysis experiment, oxygenfree $\mathrm{N}_{2}$-saturated solutions containing adenosine and varying amounts of caffeic acid were irradiated for six minutes and the decrease of absorbance of adenosine was measured. The decrease of absorbance of adenosine reflects the number of sulphate radical anions that have reacted with adenosine. From the rate constant of reaction of adenosine with $\mathrm{SO}_{4}^{--}$ $\left(k_{\text {adenosine }}=2.7 \times 10^{9} \mathrm{dm}^{3} \mathrm{~mol}^{-1} \mathrm{~s}^{-1}\right)$ the rate constant of $\mathrm{SO}_{4}^{\circ-}$ reaction with caffeic acid has been calculated to be $1.24 \times 10^{10} \mathrm{dm}^{3} \mathrm{~mol}^{-1} \mathrm{~s}^{-1}$. This value is very much similar to the one reported earlier. ${ }^{8}$

The probability of $\mathrm{SO}_{4}^{--}$radicals reacting with adenosine $\left\{p\left(\mathrm{SO}_{4}^{--}+\right.\right.$adenosine $\left.)\right\}$is calculated using the following,

$$
\begin{aligned}
& p_{\left(\mathrm{SO}_{4}^{-}+\text {adenosine }\right)}= \\
& \frac{[\text { adenosine }] k_{\text {adenosine }}}{[\text { adenosine }] k_{\text {adenosine }}-[\text { caffeic acid }] k_{\text {caffeic acid }}} .
\end{aligned}
$$


$k_{\text {adenosine }}$ and $k_{\text {caffeic acid }}$ are second-order rate constants of $\mathrm{SO}_{4}^{\circ-}$ with adenosine and caffeic acid respectively. If caffeic acid scavenges only $\mathrm{SO}_{4}^{--}$radicals and does not give rise to any other reaction (e.g. repair) the $\phi_{\text {exptl }}$ at each [caffeic acid] should be given by,

$$
\phi_{\mathrm{cal}}=\phi_{\mathrm{exptl}}^{0} \times p
$$

where $\phi_{\text {exptl }}^{0}$ is the quantum yield of oxidation of adenosine in the absence of caffeic acid, and $p$ is the probability given by (2). The $\phi_{\text {cal }}$ values at different caffeic acid concentrations are presented in table 2. If caffeic acid functions only to scavenge the $\mathrm{SO}_{4}^{\bullet-}$ radicals $\phi_{\text {cal }}$ values must be equal to $\phi_{\text {exptl }}$ values at different concentrations of caffeic acid. However, it is clear from the data in table 2 that the calculated quantum yield values $\left(\phi_{\text {cal }}\right)$ are larger than the experimentally measured quantum yield values $\left(\phi_{\text {exptl }}\right)$. This infers that the caffeic acid is acting not only as a scavenger of $\mathrm{SO}_{4}^{--}$but also preventing the chromophore loss of adenosine due to competition reaction with $\mathrm{SO}_{4}^{--}$. The difference in $\phi_{\text {cal }}$ and $\phi_{\text {exptl }}$ values is proposed to be due to the prevention of chromophore loss by adenosine radicals reaction with caffeic acid. From the rate constant of sulphate radical anion with caffeic acid, the fraction of $\mathrm{SO}_{4}^{\bullet-}$ radicals scavenged by caffeic acid (percentage scavenge = $(1-p) \times 100)$ at different [caffeic acid] were calculated (table 2). These values were a measure of protection of adenosine due to scavenging of $\mathrm{SO}_{4}^{\circ-}$ radicals by caffeic acid. Table 2 also contains the $\phi^{\prime}$ values, which are experimentally found quantum yield values at each caffeic acid concentration corrected for sulphate radical anion $\left(\mathrm{SO}_{4}^{--}\right)$scavenging by caffeic acid,

$$
\phi^{\prime}=\phi_{\operatorname{expt1}} / p
$$

The $\phi^{\prime}$ values represent the experimentally found quantum yield values if no scavenging of $\mathrm{SO}_{4}^{--}$radicals by caffeic acid occurs and hence, in the absence of repair of adenosine radicals by caffeic acid, $\phi^{\prime}$ values should all be equal to $\phi_{\text {exptl }}^{0}$. The observed decrease in the $\phi^{\prime}$ with increasing caffeic acid concentration (table 2) indicates the occurrence of repair of adenosine radicals. This decrease in $\phi^{\prime}$ values could not be attributed to the inner filter effect of caffeic acid as we have reported ${ }^{8}$ earlier that caffeic acid acts as a sensitizer and transfers energy to activate PDS to give $\mathrm{SO}_{4}^{--}$. In the present system caffeic acid as well as adenosine act as sensitizers and transfer absorbed energy to activate $\mathrm{PDS}$ to give $\mathrm{SO}_{4}^{\bullet-}$. The fraction of oxidation of adenosine inhibited by repair of adenosine radicals is given by,

$$
\text { percentage repair }=\frac{\left(\phi_{\text {exp tl }}^{0}-\phi^{\prime}\right)}{\phi_{\text {exp tl }}^{0}} \times 100
$$

The data on percentage repair is presented in table 2 .

The experimentally determined quantum yield values $\left(\phi_{\text {exptl }}\right)$ are lower than the quantum yield values $\left(\phi_{\text {cal }}\right)$ calculated using (3) under the assumption that caffeic acid acts only as a $\mathrm{SO}_{4}^{\bullet-}$ radical scavenger. This shows that caffeic acid is acting not only as an efficient scavenger of $\mathrm{SO}_{4}^{--}$but also acts as an agent for the repair of adenosine radicals. It is therefore obvious that caffeic acid is reacting not only with $\mathrm{SO}_{4}^{--}$radicals but also with adenosine radicals. The repair reaction of adenosine radicals by caffeic acid is given in scheme 1 .

In order to understand the site of attack of $\mathrm{SO}_{4}^{--}$ on purine nucleoside i.e. at the base/sugar moiety, a quantitative estimation of the base and sugar moieties present in the nucleoside has been made simultaneously and independently under kinetic conditions at different irradiation times. The results indicate that the sugar moiety is not significantly affected during the oxidation either in the absence or presence of caffeic acid. The rate of oxidation of D-ribose by $\mathrm{SO}_{4}^{--}$is lower than the rate of oxidation of nucleoside under the same experimental conditions (table 3 ). Further, the rates of oxidation of adenosine by $\mathrm{SO}_{4}^{--}$are comparable to those of the rates of oxidation of adenine (table 3 ). These results indicate that the base moiety is preferentially attacked by $\mathrm{SO}_{4}^{\cdot-}$ during the oxidation of adenosine. Therefore, the protection and repair offered by caffeic acid is thought to be mainly against base moiety oxidation.

Table 3. Rates of photooxidation of adenine, D-ribose and adenosine in presence of peroxydisulphate (PDS) under anoxic conditions.

$[\mathrm{PDS}]=4.00 \times 10^{-4} \mathrm{~mol} \mathrm{dm}^{-3}, \quad[$ substrate $]=5.00 \times 10^{-5}$ mol dm${ }^{-3}$, light intensity $=1.01 \times 10^{15}$ quanta $\mathrm{s}^{-1}, \mathrm{pH} \sim$ $7 \cdot 5$, temp $=298 \mathrm{~K}$

\begin{tabular}{lc}
\hline Substrate & $10^{8} \times$ initial rate $\left(\mathrm{mol} \mathrm{dm}^{-3} \mathrm{~s}^{-1}\right)$ \\
\hline Adenine & $0 \cdot 769$ \\
Adenosine & $0 \cdot 757$ \\
D-ribose & $0 \cdot 163$ \\
\hline
\end{tabular}




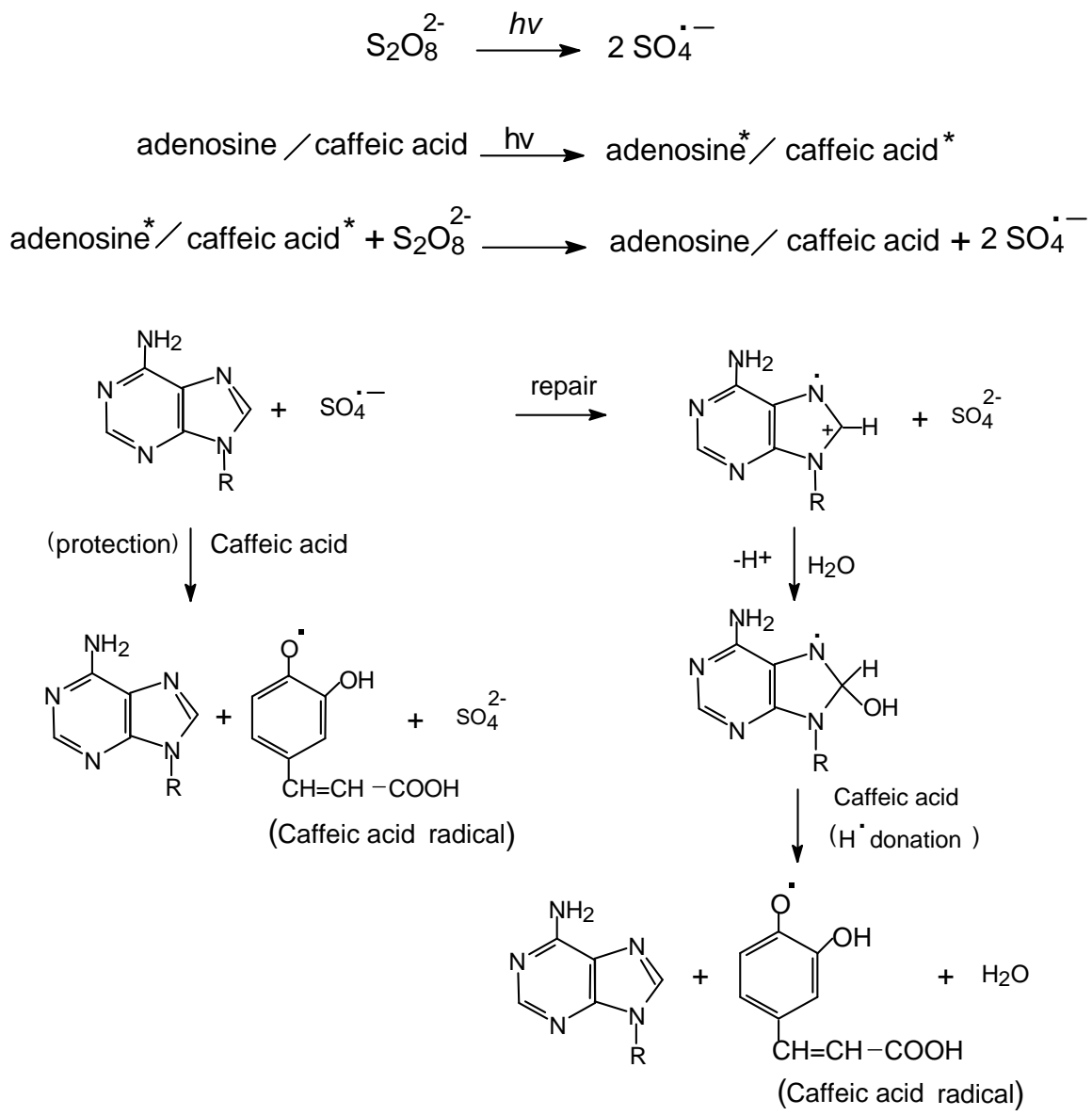

Scheme 1.

The calculated value of repair of adenosine is $91 \%$ at $5.0 \times 10^{-5} \mathrm{M}$ of caffeic acid (table 2). It is known that caffeic acid efficiently repairs the oxidizing transient radicals produced in the system. Therefore, it is obvious that the majority of the transient radicals formed on reaction of adenosine with $\mathrm{SO}_{4}^{--}$are oxidizing in nature similar to the observations reported ${ }^{8}$ in the oxidation of adenine with $\mathrm{SO}_{4}^{--}$. The reactions of protection of adenosine and repair of adenosine radicals are given in scheme 1 .

In short the competition reaction, protection and repair reactions are shown as follows:

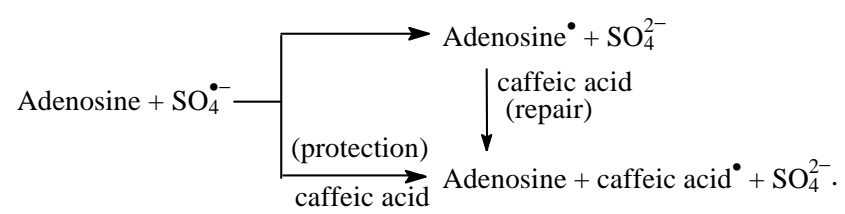

\section{Conclusions}

The rates of photooxidation of adenine, adenosine and D-ribose and the independent estimation of sugar and base moieties in the oxidation of adenosine indicate that the base moiety is preferentially attacked by $\mathrm{SO}_{4}^{--}$rather than sugar moiety. The competition kinetics of oxidation of adenosine carried out in the presence of varying concentrations of caffeic acid showed that caffeic acid acts not only as an efficient scavenger of $\mathrm{SO}_{4}^{--}$but also repairs adenosine base radicals to the extent of $91 \%$ when [caffeic acid] is $5.0 \times 10^{-5} \mathrm{M}$.

\section{Acknowledgements}

The authors thank Prof P Jayaprakash Rao for helpful discussions. MSS is thankful to the Council of Scientific and Industrial Research, New Delhi, for a fellowship.

\section{References}

1. von Sonntag C 1987 The chemical basis of radiation biology (London: Taylor \& Francis)

2. Hutchinson F 1985 Progr. Nucleic Acid Res. Mol. Biol. 32115 
3. Adinarayana M, Bothe E and Shulte-Frohlinde D 1988 Int. J. Radiat. Biol. 54723

4. Lemaire D G E, Bothe E and Sculte-Frohlinde D 1988 Int. J. Radiat. Biol. 45351

5. Sudha Swaraga M and Adinarayana M 2002 Indian J. Chem. A41 2096

6. Kapoor S, Sharma P D and Gupta Y K 1975 Talanta 22765
7. Ravi Kumar M, Thirupathi Rao $\mathbf{M}$ and Adinarayana M 1998 Indian J. Chem. A37 346

8. Sudha Swaraga M and Adinarayana M 2003 Indian J. Biochem. Biophys. 4027

9. Vieira A J S C and Steenken S 1987 J. Am. Chem. Soc. 1097441

10. Akhalaq M S, Al-Baghdad S and von Sonntag C 1987 Carbohydrate Res. 16471 